04

\title{
Моделирование электрического пробоя монокристаллов перхлората аммония в динамическом режиме
}

\author{
(C) A.B. Ханефрт \\ Кемеровский государственный университет, \\ 650043 Кемерово, Россия \\ Томский политехнический университет, \\ 634050 Томск, Россия \\ e-mail: avkhaneft@mail.ru
}

Поступило в Редакцию 31 июля 2019 г.

В окончательной редакции 18 декабря 2019 г.

Принято к публикации 26 декабря 2019 г.

\begin{abstract}
Проведено численное моделирование электрического пробоя монокристаллов перхлората аммония в динамическом режиме. Решена система дифференциальных уравнений, описывающая процессы в эквивалентной схеме генератора импульсных напряжений совместно с кинетическим уравнением ударного размножения электронов и уравнением теплового баланса. Рассчитаны зависимости электрической прочности перхлората аммония в динамическом режиме от межэлектродного расстояния и длительности переднего фронта импульса высокого напряжения. Результаты расчетов удовлетворительно согласуются с имеющимся экспериментом электрического пробоя перхлората аммония в динамическом режиме.
\end{abstract}

Ключевые слова: моделирование, электрический пробой, динамический режим, перхлорат аммония.

DOI: 10.21883/JTF.2020.06.49276.289-19

\section{Введение}

В последние десять лет появилось значительное число работ по исследованию закономерностей электрического пробоя полимерных диэлектрических пленок и энергетических материалов [1-8]. Актуальность работ [1-5] обусловлена тем, что диэлектрические пленки применяются, например, в импульсных высоковольтных конденсаторах, а диэлектрические эластомеры - в электромеханических преобразователях. В работах [1-3] показано, что экспериментальные данные по электрической прочности полимеров можно объяснить, используя ионизационный механизм пробоя диэлектриков, не связанный с развитием в них ударной ионизации. В работах $[1,5]$ рассматривается влияние скорости нарастания напряжения на образцах на их электрическую прочность. Изучение электрической прочности энергетических материалов вызвано необходимостью решения проблем безопасности при их производстве и транспортировке в связи с возможностью их электризации, а также применением их в искровых электродетонаторах [6-8]. В [8] рассмотрено влияние наноразмерных добавок на инициирование энергетических материалов высоковольтным электрическим разрядом. Предложена модель пробоя, в основе которой лежит образование бесконечного перколяционного кластера из наночастиц.

Перхлорат аммония (ПХА) является ионным диэлектриком $\left(\mathrm{NH}_{4}^{+} \mathrm{ClO}_{4}^{-}\right)$с протонной проводимостью и шириной запрещенной зоны порядка $6.06 \mathrm{eV}$ [9]. Применяется ПХА в качестве окислительного компонента смесевых ракетных видах твердого топлива в связи с большим содержанием кислорода [10].
Влияние электрического поля на термическое разложение и электрический пробой ПХА рассмотрено в работах [11-18]. В [11-13] показано, что постоянное и импульсное электрические поля уменьшают индукционный период термического разложения ПХА. В [14-16] представлены экспериментальные результаты по электрическому пробою поликристаллических таблеток ПХА. Электрическая прочность ПХА зависит от плотности таблеток, межэлектродного расстояния, длительности переднего фронта импульса высокого напряжения $\tau$, a также от дозы $D$ предварительного $\gamma$-облучения. Зависимости напряжения пробоя при разных толщинах таблеток от $\tau$ имеют вид кривых с минимумами. Для таблеток ПХА при дозе предварительного $\gamma$-облучения $D=315 \mathrm{kGy}$ минимум пропадает. Электрический пробой необлученных и облученных таблеток ПХА происходит в воздушных порах.

В работах $[17,18]$ представлены экспериментальные результаты по электрическому пробою монокристаллов ПХА импульсами высокого напряжения. Электрический пробой ПХА происходил в динамическом режиме на переднем фронте импульса высокого напряжения, т.е. в режиме перенапряжения. Осциллограмма напряжения на образце имела плавный подъем и резкий спад в случае электрического пробоя ПХА. За напряжение электрического пробоя образца полагалась напряжение в максимуме кривой. Естественно, в максимуме кривой производная $d U / d t=0$. В случае электрического пробоя ПХА в образце проскакивала электрическая искра. В $[17,18]$ показано, что электрическая прочность ПХА в динамическом режиме зависит от межэлектродного расстояния $L$ и длительности переднего фронта импуль- 
са высокого напряжения $\tau$. Зависимость электрической прочности от $\tau$ равносильна зависимости от обратной величины скорости подъема напряжения на образце.

Целью настоящей работы является численное моделирование электрического пробоя монокристаллов ПХА в динамическом режиме от межэлектродного расстояния и длительности переднего фронта импульса высокого напряжения с использованием ударного механизма размножения электронов.

\section{Постановка задачи}

На рис. 1 представлена эквивалентная схема генератора импульса высокого напряжения. На основе законов Кирхгофа для токов в узле и напряжений в электрических контурах запишем дифференциальные уравнения для напряжений на конденсаторах

$$
\begin{gathered}
\frac{d U_{G}}{d t}=-\frac{U_{G}-U_{C}}{\tau_{G}}, \\
\frac{d U_{C}}{d t}=\frac{U_{G}-U_{C}}{\tau}-\frac{U_{C}}{\left(r+R_{l}\right) C} .
\end{gathered}
$$

Здесь приняты следующие обозначения: $C_{G}-$ накопительная емкость генератора импульсного напряжения; $U_{G}-$ напряжение на накопительной емкости; $\tau_{G}=R C_{G}-$ характерное время разряда накопительной емкости; $C, R$ - емкость и сопротивление формирователя переднего фронта импульса напряжения длительностью $\tau=R C$; $U_{C}-$ напряжение на емкости $C$; $R_{l}$ - сопротивление, ограничивающее ток в цепи при электрическом пробое ПХА; $r$ - сопротивление монокристалла ПХА.

Емкости и сопротивления эквивалентной электрической схемы (рис. 1) имеют следующие значения: $C_{G}=250 \mathrm{nF}, \quad R=330 \Omega$ и $R_{l}=150 \Omega$. Емкость $C$ при численном решении уравнений (1), (2) варьировалась от 1.2 до $29 \mathrm{nF}$.

Система уравнений (1), (2) дополняется кинетическим уравнением для электронов и уравнением теплового баланса

$$
\begin{gathered}
\frac{d n}{d t}=G_{0}+\alpha v_{d} n-k_{r} n^{2}-\frac{v_{d} n}{L}, \\
c \rho \frac{d T}{d t}=\sigma E^{2}+Q,
\end{gathered}
$$

где $n$ - концентрация электронов; $\alpha$ - коэффициент ударной ионизации электронов; $k-$ константа

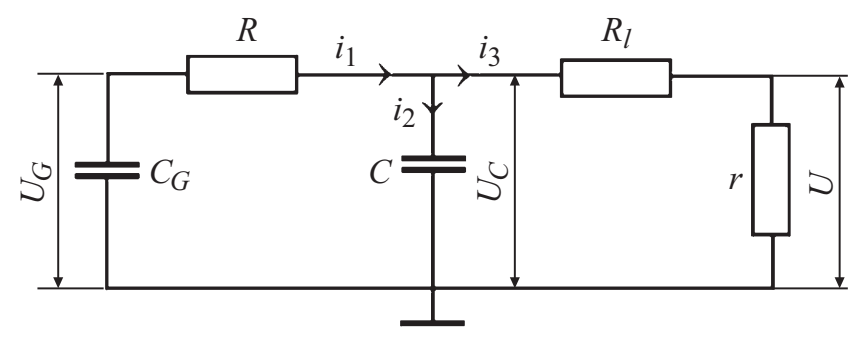

Рис. 1. Эквивалентная схема генератора. рекомбинации электронов с дырками; $v_{d}-$ дрейфовая скорость электронов; $T$ - температура образца; $\rho$ и $c-$ плотность и удельная теплоемкость ПХА; $Q-$ удельная скорость тепловыделения при разложении ПХА; $\sigma$ электронная удельная проводимость образца.

Кинетическое уравнение (3) для электронов включает в себя процессы ударного размножения электронов и их гибель вследствие рекомбинации с дырками и выноса из диэлектрика [19]. Естественно, в данной наиболее простой записи уравнения (3) не учитывается образование объемного заряда, а также захвата электронов на примесные центры [19], например, образованные протонами. Да это и невозможно сделать корректно, так как ПХА - практически не исследованное соединение с точки зрения физики полупроводников, как например, классические полупроводники германий или кремний. В уравнение (3) включено дополнительное слагаемое генерационный член $G_{0}$. Это слагаемое учитывает образование первичных электронов в объеме диэлектрика вследствие фоновой генерации или экзоэлектронной эмиссии из электродов [20]. Кроме того, под $G_{0}$ можно понимать скорость опустошения ловушек в электрическом поле вследствие эффекта Френкеля [21]. Если не учитывать в уравнении (3) слагаемое $G_{0}$, то ударное размножение электронов не происходит вследствие выноса начальных электронов из объема диэлектрика. Расчеты проводились при $G_{0}=10^{3} \mathrm{~cm}^{-3} \mathrm{~s}^{-1}$.

Дрейфовая скорость и электронная проводимость образца определяются выражениями

$$
v_{d}=\mu E, \sigma=q \mu n,
$$

где $\mu-$ подвижность электронов; $E=U / L-$ напряженность электрического поля а образце ПХА; $q$ элементарный заряд. Расчеты проводились при подвижности электронов $\mu=0.2 \mathrm{~cm}^{2} /(\mathrm{V} \cdot \mathrm{s})$. Значение подвижности электронов подбиралось таким образом, чтобы как можно лучше описать экспериментальные результаты по зависимости электрической прочности монокристаллов ПХА от межэлектродного расстояния [17]. Вкладом дырок в ударное размножение и проводимость пренебрегли, так как подвижность дырок в ионных кристаллах значительно меньше подвижности электронов.

Напряжение на образце ПХА вычислялось по формуле

$$
U=U_{C} \frac{r}{r+R_{l}} .
$$

Сопротивление образца рассчитывалось по формуле

$$
r=\frac{L}{S\left(\sigma+\sigma_{0}\right)},
$$

где $S=\pi d^{2} / 4 \quad$ - площадь электрода; $\sigma_{0}-$ протонная удельная проводимость образца, равная $\sim 10^{-14}(\Omega \cdot \mathrm{cm})^{-1}$ при $T=300 \mathrm{~K}[9] ; d=0.7 \mathrm{~mm}-$ диаметр электродов [17]. 
Коэффициент ударной ионизации электронов вычислялся по выражению [18]:

$$
\alpha=2 \cdot 10^{4} \exp \left[-\left(\frac{8.4 \cdot 10^{6}}{E}\right)^{0.4}\right], \mathrm{cm}^{-1} .
$$

Константа рекомбинации электронов $k_{r}$ в ПХА полагалась порядка $10^{-11} \mathrm{~cm}^{3} / \mathrm{s}$. Константа $k_{r}$ такого порядка измерена, например, в ионном кристалле $\mathrm{AgBr}[22]$.

Для ПХА плотность монокристалла $\rho=$ $=1.95 \cdot 10^{3} \mathrm{~kg} / \mathrm{m}^{3} \quad[9], \quad$ удельная теплоемкость $c=660.0+1.72 \cdot T \mathrm{~J} /(\mathrm{kg} \cdot \mathrm{K}) \quad[23] . \quad$ Скорость тепловыделения

$$
Q=\frac{\rho Q_{m} Z}{M} \exp \left(-\frac{E_{a}}{R T}\right),
$$

где $Q_{m}=171.24 \mathrm{~kJ} / \mathrm{mol} \quad-\quad$ тепловой эффект реакции термического разложения ПХА [24]; $M=117.45 \cdot 10^{-3} \mathrm{~kg} / \mathrm{mol}$ - молярная масса ПХА; $Z=10^{8} \mathrm{~s}^{-1}$ - частотный фактор; $E_{a}=125.6 \mathrm{~kJ} / \mathrm{mol}$ энергия активации реакции термического разложения ПХА. Кинетические параметры для $Z$ и $E_{a}$ взяты из [24] для температурного интервала $468-553 \mathrm{~K}$.

Система дифференциальных уравнений (1)-(4) имеет следующие начальные условия:

$U_{G}(0)=10 \mathrm{kV}, U_{C}(0)=0, n(0)=1 \mathrm{~cm}^{-3}, T(0)=330 \mathrm{~K}$.

Определим функциональную зависимость напряжения $U$ на образце при $t<t^{*}$, где $t^{*}-$ динамическое время задержки электрического пробоя диэлектрика. Положим, что $r=\infty$. Тогда уравнение (2) примет вид

$$
\frac{d U_{C}}{d t}=\frac{U_{G}-U_{C}}{\tau} .
$$

Решая систему дифференциальных уравнений (1) и (7), получим выражения для напряжений на емкостях $C_{G}$ и $C$ :

$$
\begin{gathered}
U_{G}(t)=U_{G}(0)\left[\frac{\tau_{0}}{\tau}+\left(1-\frac{\tau_{0}}{\tau}\right) \exp \left(-\frac{t}{\tau_{0}}\right)\right], \\
U_{C}(t)=U_{G}(0) \frac{\tau_{0}}{\tau}\left[1-\exp \left(-\frac{t}{\tau_{0}}\right)\right]
\end{gathered}
$$

где

$$
\tau_{0}=\frac{\tau_{G} \tau}{\tau_{G}+\tau}=\frac{C_{G}}{C_{G}+C} \tau
$$

Учитывая, что $C_{G} \gg C$ и $r=\infty$, окончательно получим зависимость напряжения на образце и емкости $C$ от времени и крутизны переднего фронта импульса

$$
U(t)=U_{C}(t)=U_{G}(0)\left[1-\exp \left(-\frac{t}{\tau}\right)\right] .
$$

Таким образом, крутизна переднего фронта импульса напряжения зависит только от емкости $C$. Выражение (10) совпадает с выражением для зависимости переднего фронта напряжения от времени, приведенного в работе [1].

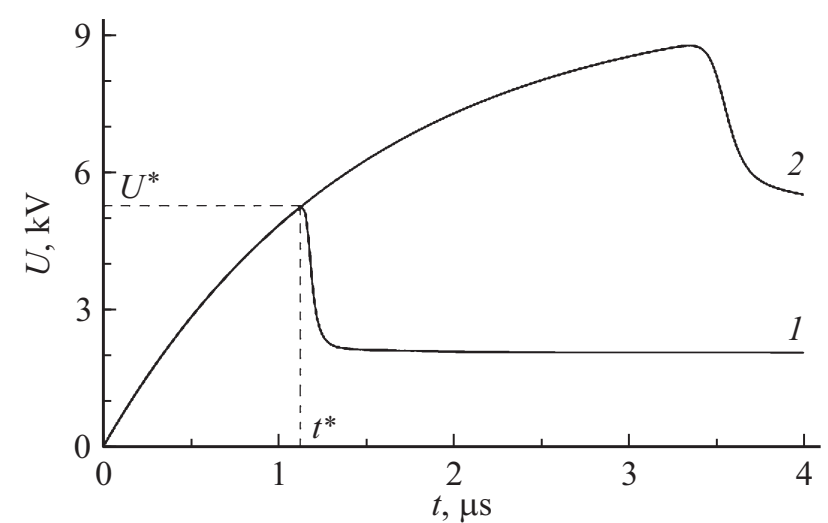

Рис. 2. Зависимость напряжения на образце ПХА от времени при $\tau=1.5 \mu \mathrm{s}$ и $L=0.01(1), 0.03 \mathrm{~cm}(2)$ (расчет).

\section{Результаты численных расчетов и их обсуждение}

Система обыкновенных дифференциальных уравнений (1) - (4) с начальными условиями (6) решалась численно методом Рунге-Кутта 4-го порядка точности [25] совместно с уравнением (5). Некоторые результаты численного моделирования электрического пробоя монокристаллов ПХА в динамическом режиме приведены на рис. 2-5.

На рис. 2 приведены расчетные кривые зависимости напряжения $U$ на образце ПХА от времени при длительности переднего фронта импульса высокого напряжения $\tau=1.5 \mu \mathrm{s}$ и межэлектродных расстояниях $L=0.01$ (1) и $0.03 \mathrm{~cm} \mathrm{(2).} \mathrm{За} \mathrm{напряжение} \mathrm{пробоя}$ при численном решении системы уравнений (1)-(4) принималось напряжение $U^{*}$ в точке изменения знака производной $d U / d t$, т.е. в точке $U=U^{*}$ производная $d U / d t=0$ (рис. 2, кривая 1 ) $[1,19]$. Для кривой 1 $(L=0.01 \mathrm{~cm})$ напряжение пробоя $U^{*} \approx 5.25 \mathrm{kV}$, а динамическое время задержки электрического пробоя $t^{*}=1.137 \mu \mathrm{s}$. Сопротивление образца ПХА в данный момент времени равно $r^{*} \approx 24.2 \mathrm{k} \Omega$, а ток через образец $i_{3}^{*} \approx 0.217 \mathrm{~A}$ (рис. 3). Расчеты показали, что ток $i_{3}$ за время $\Delta t=0.137 \mu \mathrm{s}$ вследствие ударного (цепного) размножения возрос на пять порядков. Это говорит о том, что время развития электрического пробоя при ударной ионизации значительно меньше динамического времени задержки электрического пробоя. Концентрация электронов в момент пробоя $n\left(t^{*}\right)=3.36 \cdot 10^{15} \mathrm{~cm}^{-3}$. Скорости ударного размножения, рекомбинации и выноса электронов из объема в момент пробоя соответственно равны

$$
\begin{gathered}
\alpha v_{d} n=0.34 \cdot 10^{24} \mathrm{~cm}^{-3} \mathrm{~s}^{-1}, k_{r} n^{2}=0.11 \cdot 10^{21} \mathrm{~cm}^{-1} \mathrm{~s}^{-1}, \\
\frac{v_{d} n}{L}=0.35 \cdot 10^{23} 4 \mathrm{~cm}^{-3} \mathrm{~s}^{-1} .
\end{gathered}
$$

Из сравнения данных скоростей видно, что основным каналом гибели электронов является их вынос из объема образца, а не рекомбинация. 


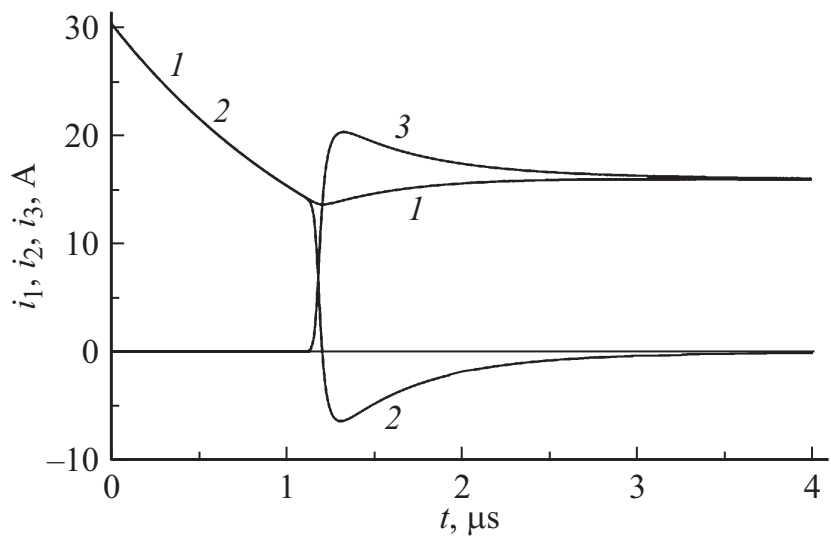

Рис. 3. Зависимости токов $i_{1}(1), i_{2}(2)$ и $i_{3}$ (3) от времени в эквивалентной схеме генератора импульсного напряжения при $\tau=1.5 \mu$ и и $L=0.01 \mathrm{~cm}$.

Учитывая неравенство $r^{*} \gg R_{l}$, из выражения (5) имеем, что $U^{*} \approx U_{C}$ в момент пробоя. Расчеты показали, что $U_{C}\left(t^{*}\right) \approx 5.28 \mathrm{kV}$. Значение $U^{*}$ можно оценить и по формуле (10). Так, при $t^{*}=1.137$ и $\tau=1.5 \mu \mathrm{s}$ из (10) имеем $U^{*} \approx 5.31 \mathrm{kV}$, т.е. немного завышенное значение для напряжения пробоя.

Электрические токи в эквивалентной схеме вычислялись по формулам

$$
i_{1}=\frac{U_{G}-U_{C}}{R}, i_{2}=\frac{U_{G}-U_{C}}{R}-\frac{U_{C}}{r+R_{l}}, i_{3}=i_{1}-i_{2} .
$$

Результаты расчетов токов изображены на рис. 3. Как видно из рис. 3 , до начала развития электрического пробоя ток $i_{1} \approx i_{2}$, а ток $i_{3} \approx 0$. После электрического пробоя ток $i_{2}$ меняет свое направление, т.е. емкость $C$ начинает разряжаться. Это приводит к появлению максимума на зависимости $U_{C}(t)$ при $t=1.205 \mu \mathrm{s}$. Напряжение на емкости в максимуме $U_{C}=5.41 \mathrm{kV}$. Производная в данный момент времени

$$
\frac{d U_{C}}{d t}=\frac{U_{G}-U_{C}}{\tau}-\frac{U_{C}}{\left(r+R_{l}\right) C}=0 .
$$

Из данного выражения имеем, что $i_{1}=i_{3}, i_{2}=0$. Причем ток $i_{1}$ имеет минимум (рис. 3 , кривая 1 ). Возрастание тока $i_{1}$ после минимума вызвано разрядом емкости $C$ через сопротивления $R_{l}$ и $r$.

Спад напряжения на образце после электрического пробоя происходит вследствие уменьшения сопротивления образца. Как показали расчеты, изменением температуры ПХА к моменту пробоя можно пренебречь. Температура резко начинает возрастать после электрического пробоя. Например, к моменту времени $t=1.5 \mu \mathrm{s}$ температура образца увеличивается примерно на $150.0 \mathrm{~K}$ вследствие джоулева разогрева, концентрация электронов $n \approx 7.31 \cdot 10^{17}$ и ток через образец $i_{3} \approx 19.4 \mathrm{~A}$. Вклад экзотермической реакции разложения ПХА в повышение температуры образца к данному моменту времени незначителен.
В настоящее время общепринятым является протонный механизм термического разложения ПХА [9]. Электронный механизм [26], согласно которому первичным элементарным актом разложения ПХА является переход электрона от аниона к катиону

$$
\mathrm{NH}_{4}^{+}+\mathrm{ClO}_{4}^{-} \rightarrow \mathrm{NH}_{4}^{0}+\mathrm{ClO}_{4}^{0},
$$

был отвергнут в связи с тем, что ПХА является широкозонным диэлектриком. Однако образующиеся при ударной ионизации электроны $\left(e^{-}\right)$и дырки $\left(h^{+}\right)$могут инициировать неравновесную экзотермическую реакцию разложения ПХА (12). Влияние ионизирующего излучения на разложения ПХА показано, например, в [9].

Образование сквозного канала диаметром несколько микрон в ПХА при электрическом пробое может быть обусловлено пинч-эффектом [21], который приводит к возрастанию плотности тока в центре кристалла ПХА. Таким образом, можно предположить, что выгорание сквозного канала в ПХА происходит после падения напряжения на образце.

На рис. 4 приведена зависимость электрической прочности ПХА от межэлектродного расстояния при $\tau=1.5 \mu$ s. Как видно из рис. 4, результаты расчетов удовлетворительно согласуются с экспериментом [17]. Необходимо отметить, что в работе [17] допущена неточность. Точка для $E^{*}$ при $L=0.08$ получена при $U_{G}(0)=14 \mathrm{kV}$. При $U_{G}(0)=10 \mathrm{kV}$ электрический пробой ПХА не происходит.

На рис. 5 представлены экспериментальные [18] и расчетные зависимости электрической прочности ПХА от длительности переднего фронта импульса высокого напряжения $\tau$ при межэлектродном расстоянии $L=0.03 \mathrm{~cm}$ (треугольники и расчетная кривая 1 ) и $L=0.01$ (точки и расчетная кривая 2). Как видно из рис. 5, расчетная кривая 1 при $L=0.03 \mathrm{~cm}$ количественно удовлетворительно согласуется с результатами

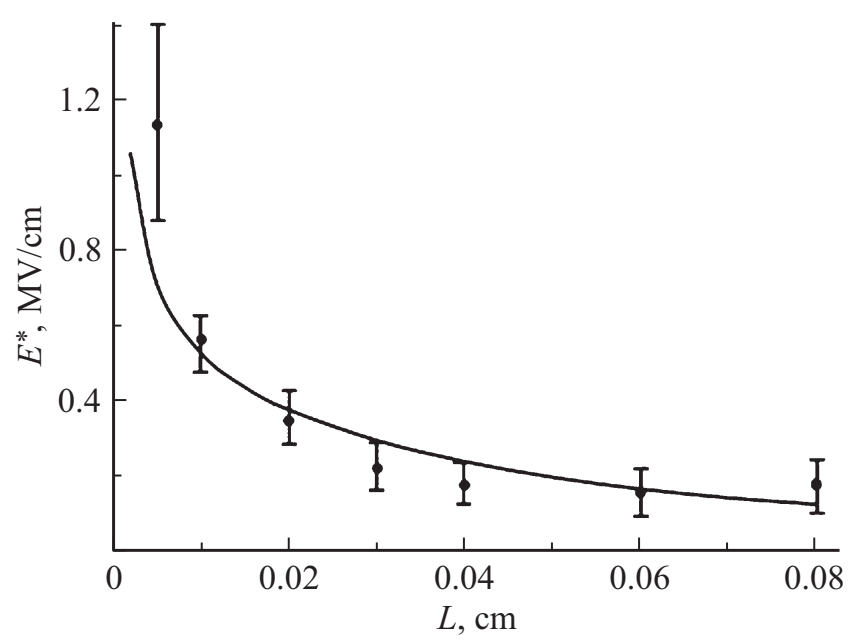

Рис. 4. Зависимость электрической прочности ПХА от межэлектродного расстояния $L$ при $\tau=1.5 \mu \mathrm{s}$ : точки - эксперимент [17], линия — расчет. 


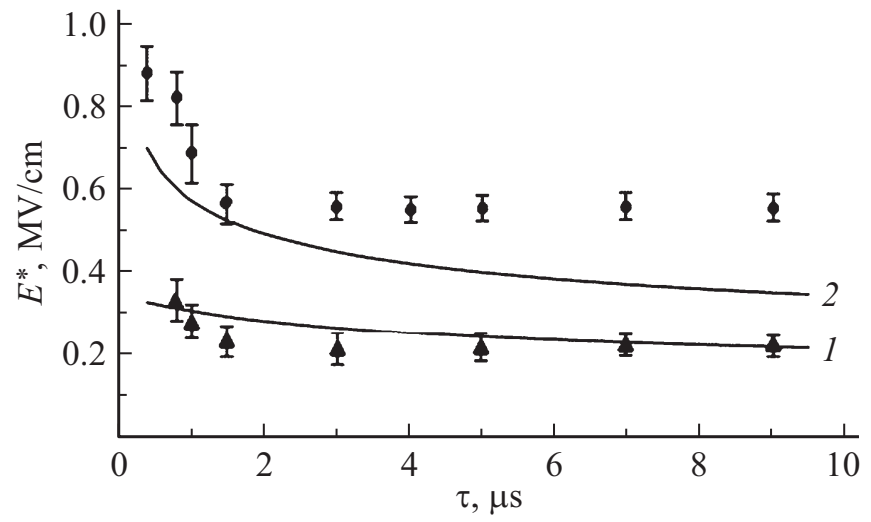

Рис. 5. Зависимость электрической прочности ПХА от длительности переднего фронта импульса высокого напряжения $\tau$ : $\mathbf{\Lambda}, \bullet$ - эксперимент при $L=0.03$ и $0.01 \mathrm{~cm}[18]$; кривые $1,2-$ расчет при $L=0.03$ и $0.01 \mathrm{~cm}$.

экспериментов. Расчетные значения электрической прочности при $L=0.01 \mathrm{~cm}$ отличаются от экспериментальных данных примерно на 40\%. Кроме того, видно, что экспериментальные значения электрической прочности ПХА при $\tau>1.5 \mu \mathrm{s}$ не зависят от $\tau$. Согласно [27], независимость электрической прочности диэлектриков при больших $\tau$ может являться следствием образования объемного заряда.

Из рис. 5 видно, что расчетные значения $E^{*}$, наоборот, зависят от $\tau$. Причем чем больше $\tau$, тем слабее становится зависимость $E^{*}$ от $\tau$. Это можно показать качественно, если от выражения (10) взять производную по $\tau$ :

$$
\left.\frac{d E(t)}{d \tau}\right|_{t=t^{*}} \approx-\frac{t^{*} U_{G}(0)}{\tau^{2} L} \exp \left(-\frac{t^{*}}{\tau}\right)
$$

Так же из данного выражения видно, что чем меньше межэлектродное расстояние, тем круче ведет себя зависимость $E^{*}(\tau)$, что согласуется с результатами расчетов и качественно с экспериментом при $\tau \leq 1.5 \mu \mathrm{s}$ (рис. 5). Следовательно, время задержки электрического пробоя монокристаллов ПХА определяется в основном временем заряда емкости $C$, т. е. временем подъема напряжения на образце, а не характерным временем развития ударного размножения электронов. Вот поэтому результаты расчетов напряжения электрического пробоя ПХА в динамическом режиме удовлетворительно согласуются с экспериментом.

Определим сдвиг протонов в электрическом поле:

$$
\begin{aligned}
\Delta x & =\mu_{p} \frac{U_{G}(0)}{L} \int_{0}^{t^{*}}\left[1-\exp \left(-\frac{t}{\tau}\right)\right] d t \\
& =\mu_{p} \frac{U_{G}(0)}{L}\left[t^{*}-\tau+\tau \exp \left(-\frac{t^{*}}{\tau}\right)\right] .
\end{aligned}
$$

Подвижность протонов [9]

$$
\mu_{p}=20 \exp \left(-W_{p} / R T\right) \mathrm{cm}^{2} /(\mathrm{V} \cdot \mathrm{s}),
$$

где $W_{p}=78.14 \mathrm{~kJ} / \mathrm{mol} \quad$ энергия активации подвижности протонов. При $L=0.01 \mathrm{~cm}, \tau=1.5 \mu \mathrm{s}$, $t^{*}=1.137 \mu \mathrm{s} \quad$ и $T=300 \mathrm{~K} \quad$ имеем из (14), что $\Delta x=1.65 \cdot 10^{-12} \mathrm{~cm}$. Следовательно, поляризацией ПХА вследствие смещения протонов за динамическое время задержки электрического пробоя монокристаллов ПХА можно пренебречь.

Таким образом, удовлетворительное совпадение результатов расчета электрической прочности ПХА от межэлектродного расстояния и длительности переднего фронта импульса напряжения с экспериментальными результатами позволяет считать доказанным, что электрический пробой монокристаллов в динамическом режиме ПХА происходит вследствие ударного размножения электронов в электрическом поле. Для лучшего описания экспериментов по зависимости электрической прочности от толщины диэлектрика и длительности переднего фронта импульса напряжения необходимо учитывать влияние объемного заряда [27,28].

\section{Заключение}

В работе проведено моделирование электрического пробоя монокристаллов в динамическом режиме ПХА. Численно решены система дифференциальных уравнений для электрических контуров эквивалентной схемы генератора импульсных напряжений, кинетическое уравнение для электронов и уравнение теплового баланса. В кинетическом уравнении для электронов учитывались процессы ударного ионизации, рекомбинации и выноса электронов из объема ПХА. Рассчитаны зависимости электрической прочности ПХА от межэлектродного расстояния и длительности переднего фронта импульса высокого напряжения. Результаты расчетов удовлетворительно согласуются с экспериментом по электрическому пробою монокристаллов ПХА в динамическом режиме. Время задержки электрического пробоя монокристаллов ПХА определяется в основном временем подъема напряжения на образце, а не характерным временем развития ударного размножения электронов. Спад напряжения на образце после электрического пробоя обусловлен уменьшением сопротивления диэлектрика. Расчеты показали, что джоулевым разогревом в момент пробоя ПХА можно пренебречь.

\section{Финансирование работы}

Работа выполнена при финансовой поддержке Российского научного фонда (грант № 18-13-00031).

\section{Конфликт интересов}

Автор заявляет, что у него нет конфликта интересов. 


\section{Список литературы}

[1] Закревский В.А., Пахотин В.А., Сударь Н.Т. // ЖТФ. 2019. T. 89. Вып. 1. С. 120-125. [Zakrevskii V.A., Pakhotin V.A., Sudar N.T. // Tech. Phys. 2018. Vol. 63. N 12. P. 1814-1819.] DOI: 10.21883/JTF.2019.01.46972.98-18

[2] Закревский В.А., Пахотин В.А., Сударь Н.Т. // ЖТФ. 2017. T. 87. Вып. 2. C. 249-253. [Zakrevskii V.A., Pakhotin V.A., Sudar N.T. // Tech. Phys. 2017. Vol. 62. N 2. P. 276-281.] DOI: 10.21883/JTF.2017.02.44133.1907

[3] Закревский В.А., Сударь Н.Т. // ФТТ. 2013. Т. 55. Вып. 7. C. 1298-1303. [Zakrevskii V.A., Sudar' N.T. // Phys. Solid State. 2013. Vol. 55. N 7. P. 1395-1400.] DOI: $10.1134 / \mathrm{S} 1063783413070354$

[4] Закревский В.А., Сударь Н.T. // ФТТ. 2005. Т. 47. Вып. 5. C. 931-936. [Zakrevskii V.A., Sudar' N.T. // Phys. Solid State. 2005. Vol. 47. N 5. P. 961-967.]

[5] Смирнов И.В., Springhetti R., Морозов В.А., Лукин А.A. // ЖТФ. 2018. Т. 88. Вып. 1. С. 151-153. [Smirnov I.V., Springhetti R., Morozov V.A., Lukin A.A. // Tech. Phys. 2018. Vol. 63. N 1. P. 152-154.] DOI: 10.21883/JTF.2018.01.45500.2177

[6] Садовничий Д.Н., Милехин Ю.М., Лопаткин С.А., Скрипина Т.С., Малинин С.А., Гросс И.Н. // ФГВ. 2019. T. 55. № 2. C. 108-118. [Sadovnichii D.N., Milekhin Yu.M., Lopatkin S.A., Skripina T.S., Malinin S.A., Gross I.N. // Combust., Explosion and Shock Waves. 2019. Vol. 55. N 2. P. 220-229.] DOI: $10.15372 / F G V 20190211$

[7] Садовничий Д.Н., Милехин Ю.М., Лопаткин С.А., Важсов В.Ф., Гусев С.А., Бутенко Е.А. // ФГВ. 2010. Т. 46. № 4. C. 107-115. [Sadovnichii D.N., Milekhin Yu.M., Lopatkin S.A., Vazhov V.F., Gusev S.A., Butenko E.A. // Combust., Explosion and Shock Waves. 2010. Vol. 46. N 4. P. 464-471.]

[8] Савенков Г.Г., Рашковский С.А., Морозов В.А., Лукин А.А., Оськин И.А., Брагин В.А., Шамильянов А.В. // ЖТФ. 2017. Т. 87. Вып. 9. С. 1327-1335. [Savenkov G.G., Rashkovskii S.A., Morozov V.A., Lukin A.A., Os'kin I.A., Bragin V.A., Shamil'yanov A.V. // Tech. Phys. 2017. Vol. 62. N 9. P. 1337-1345.] DOI: $10.1134 /$ S10 63784217090225

[9] Болдырев В.В. Реакционная способность твердых веществ. Новосибирск: Изд-во СО РАН, 1997. 304 с.

[10] Гусаченко Л.К., Зарко В.Е., Зырянов В.Я., Бобрышев В.П. Моделирование процессов горения твердых топлив. Новосибирск: Наука, 1985. 183 с.

[11] Лаптенков Б.К., Раевский А.В., Манелис Г.Б., Абруков С.А. // ДАН СССР. 1980. Т. 250. № 5. С. 1185-1187.

[12] Лаптенков Б.К., Абруков С.А. // Физика горения и методы исследования: Сб. статей. Вып. 8. Чебоксары. 1978. C. 34-40.

[13] Ханебы И.Г. // Тез. докл. 10-го Всесоюзного совещания по кинетике и механизму химических реакций в твердом теле. Черноголовка. 1989. С. 105-106.

[14] Сухушин Ю.Н., Ханеøт И.Г. // ЖПМТФ. 1990. Т. 3. № 3. C. 12-15. [Sukhushin Yu.N., Khaneft I.G. // J. Appl. Mechan. Tech. Phys. 1990. Vol. 31. N 3. P. 351-353.]

[15] Khaneft I.G., Khaneft A.V. // Energetic Materials for High Performance, Insensitive Munitions and Zero Pollution: 41th International Annual Conference of ICT, Federal Republic of Germany, Karlsruhe, 23-26 iune. 2010. P. 61-1-61-12.
[16] Ханефт И.Г., Ханефб А.В. // Химическая физика и мезоскопия. 2013. Т. 15. № 1. С. 034-040.

[17] Ханефт И.Г., Ханефт А.В. // ЖТФ. 1995. Т. 65. Вып. 6. C. 200-203. [Khaneft I.G., Khaneft A.V. // Tech. Phys. 1995. Vol. 40. N 6. P. 631-633.]

[18] Ханефт И.Г., Ханебт А.В. // ЖТФ. 2000. Т. 70. Вып. 4. C. 42-45. [Khaneft I.G., Khaneft A.V. // Tech. Phys. 2000. Vol. 45. N 4. P. 423-426.]

[19] Франи, В. Пробой диэлектриков. М.: ИЛ, 1961. 208 с.

[20] Райзер Ю.П. Физика газового разряда. М.: Наука, 1987. $536 \mathrm{c}$.

[21] Шалабутов Ю.К. Введение в физику полупроводников. Л.: Наука, 1969. 292 с.

[22] Голованов Б.И., Новиков Г.Ф., Алфимов М.В. // ЖНиПФиК. 1991. Т. 36. № 4. С. 335-337.

[23] Фролов Ю.В., Зенин А.А., Яковлев В.П. // ФГВ. 1969. Т. 5. № 4. C. 544-549.

[24] Манелис Г.Б., Назин Г.М., Рубцов Ю.И., Струнин В.А. Термическое разложение и горение взрывчатых веществ и порохов. М.: Наука, 1996. 224 с.

[25] Мудров А.Е. Численные методы для ПЭВМ на языках Бейсик, Фортран и Паскаль. Томск: МП „РАСКО“, 1991. $272 \mathrm{c}$.

[26] Keenan A.G., Siegmund R.F. // Quart. Rev. Chem. Soc. London. 1969. Vol. 23. N 3. P. 430-452. DOI: $10.1039 / \mathrm{QR} 9692300430$

[27] Карасев В.И., Коробов А.И., Абалмазова М.Г. // Радиотехника и электроника. 1971. Т. 16. № 3. С. 405-407.

[28] Воробьев А.А., Воробьев Г.А. Электрический пробой и разрушение твердых тел. М.: Высш. шк., 1966. 224 с. 